care they prefer to administer rather than to impose a unitary system. This is particularly important given that almost $90 \%$ of general practitioners have been approved to run chronic disease management programmes for diabetes under the new contract. $^{8}$

Glycaemic control is the most common outcome measured in diabetes care, which is justifiable given that the diabetes control and complications trial showed that good glycaemic control delayed the onset and slowed the progression of diabetes related complications. ${ }^{9}$ Nevertheless, glycaemic control incompletely measures quality of care because tight control increases the risk of hypoglycaemia. ${ }^{10}$ Efforts to improve control may also upset some patients as it usually entails a more demanding regimen. Both of these factors can seriously affect patients' quality of life. Evaluations of shared care should therefore incorporate outcome measures of importance to patients. The St Vincent's Declaration recognises that psychological factors are important, and guidelines for promoting patients' psychological wellbeing have been published $^{11}$ and several measures are now available. ${ }^{12}$

As glycaemic control and quality of life often conflict over the short and long term, patients' preferences become of paramount importance in determining the optimal type of care. Because patients' preferences may affect outcomes-for example, by influencing compliance and other behaviourthey need to be taken into consideration in the design of evaluative trials. ${ }^{13} \mathrm{~A}$ simple answer to the question of whether shared care is cost effective or even clinically effective is unlikely, not least because optimal care might differ between patients and practitioners. Shared care is not a panacea and its effectiveness and cost effectiveness are uncertain. We need trials that take into account the complexities and interactions of setting, provider interest, and consumer preference.

AMANDA J SOWDEN

Research fellow

TREVOR A SHELDON

Director

NHS Centre for Reviews and Dissemination,

University of York,

York YO1 5DD

Department of Medicine,

Medical School, Newcastle University,

Newcastle upon Tyne NE2 4HH

1 NHS Management Executive. Integrating primary and secondary health care. London: Departmen of Health, 1991.

2 Hickman M, Drummond N, Grimshaw J. A taxonomy of shared care for chronic disease. $f$ Public Health Med (in press).

3 Greenhalgh PM. Shared care for diabetes: a systematic review. Royal College of General Practitioner 1994 (occasional paper 67).

4 Wood J. A review of diabetes care initiatives in primary care settings. Health Trends 1990;22:39-43. 5 Chalmers I. Assessing the effects of health technologies, principles, practice, proposals. A paper prepared by the advisory group on Health Technology Assessment for the Director of Research and Development NHS Management Executive. London: Department of Health, 1992.

6 Grampian Asthma Study of Integrated Care (GRASSIC). Integrated care for asthma: a clinical, social, and economic evaluation. BMF 1994;308:559-64.

7 Pringle M, Stewart-Evans C, Coupland C, Williams I, Allison S, Sterland J. Influences on contro in diabetes mellitus: patient, doctor, practice, or delivery of care? BMf 1993;306:630-4

8 Clinical Standards Advisory Group. Standards of clinical care for people with diabetes. London: HMSO, 1994.

9 Diabetes Control and Complications Trial Research Group. The effect of intensive treatment of diabetes on the development and progression of long-term complications in insulin-dependen mellitus. N Engl f Med 1993;329:977-86.

10 Teuscher A, Reinli K, Nathan DM. Severe hypoglycaemia in diabetes control and complications trial. Lancet 1994;343:1097-8.

11 Bradley C, Gmsu DS. Guidelines for encouraging psychological well-being: report of a working group of the World Health Organisation regional office for Europe and International Diabetes Federation European Region St Vincent Declaration Action Programme for Diabetes. Diabetic Medicine 1994;11:510-6.

12 Bradley C. Handbook of psychology and diabetes: a guide to psychological measurement in diaberes research and practice. Switzerland: Harwood Academic, 1994.

13 Brewin CR, Bradley C. Patient preferences and randomised clinical trials. BMf 1989;299:313-5.

\title{
Primary orthostatic tremor
}

\section{Causes difficulty in standing still}

Heilman described the clinical features of primary orthostatic tremor 10 years ago. ${ }^{1}$ Subsequent studies have elucidated the specific neurophysiological features of the condition, which clearly distinguish it from other tremulous disorders of the legs. ${ }^{2-4}$ Although the condition is rare, the incidence of this recently described condition remains unknown. Identification of cases is still increasing, with wider recognition of the characteristic clinical symptoms. Doctors should be aware of the typical symptom complex of orthostatic tremor, as many patients are wrongly labelled as suffering from psychiatric symptoms. ${ }^{5}$

The most prominent and characteristic symptom reported by patients with primary orthostatic tremor is unsteadiness when standing still-for example, at supermarket check outs or bus stops. By contrast, patients have little or no difficulty in walking, which typically relieves their symptoms. ${ }^{34}$ Despite the condition's name few patients complain specifically of tremor. Examination, when the patient attempts to stand still, reveals a fine rippling of the muscles of the legs that may be easier to feel than to see. After a short interval, the patient becomes increasingly unsteady and is forced to take a step to regain balance. Falls and injuries, however, are rare.

The diagnosis is confirmed neurophysiologically. ${ }^{2-4}$ Surface electromyographic recordings show rhythmic activation of lower limb muscles at a frequency of 14-18 Hz. Within any individual patient, the frequency is the same in all muscles and fixed. This frequency of muscle activity is characteristic of the condition and is much higher than can be produced voluntarily and higher than that seen in other tremulous conditions (for example, essential tremor or Parkinson's disease, in which the frequency usually lies between 3 and $8 \mathrm{~Hz}^{6}$ ). Interestingly, rhythmic activation of upper limb muscles at the same frequency can be seen if patients use their arms to maintain posture-for example, by standing on all fours. ${ }^{347}$

The cause of the condition is unknown. The neurophysiological abnormalities suggest a brain stem disturbance, and recent positron emission tomography studies have shown increased activity in the cerebellum in comparison with controls when patients hold their arms outstretched (which in some patients also brings out a tremor) ${ }^{8}$ Results on radiological examination are normal, and no other disturbance of brain stem function has been associated with the condition. The relation of primary orthostatic tremor to essential tremor is disputed..$^{349}$ The condition affects both sexes and the age of onset is usually in the sixth or seventh decade of life, although it may begin as early as the third decade. Some patients have had symptoms for more than 20 years.

Although no specific treatment currently exists, patients are often relieved to know the diagnosis, particularly if a psychiatric cause had previously been suspected. Clonazepam, ${ }^{1479}$ phenobarbitone, ${ }^{47}$ primidone, ${ }^{4910}$ and sodium valproate ${ }^{4}$ have been used with occasional success. $B$ Blockers and alcohol are ineffective. Stools (in the kitchen) and shooting sticks with rubber ends (for bus queues) may be helpful. With a better understanding of the condition more 
specific treatment may become available. In the meantime, it is important not to misdiagnose primary orthostatic tremor as a psychiatric illness for want of a careful clinical examination and lack of awareness of the condition.

T C BRITTON Senior registrar in neurology

The National Hospital,

London WCIN 3BG

P D THOMPSON

Associate professor of medicine

Royal Adelaide Hospital,

Adelaide,

South Australia
1 Heilman KM Orthostatic tremor. Anch Neurol 1984;41:880-1.

2 Thompson PD, Rothwell JC, Day BL, Berardelli A, Dick JPR, Kachi T, et al. The physiology of orthostatic tremor. Arch Neurol 1986;43:584-7.

3 Britton TC, Thompson PD, van der Kamp W, Rothwell JC, Day BL, Findley LJ, et al. Primary orthostatic tremor: further observations in six cases. $\mathcal{F}$ Neurol 1992;239:209-17.

4 McManis PG, Sharbrough FW. Orthostatic tremor: clinical and electrophysiological characteristics. Muscle Nerve 1993;16:1254-60.

5 Korthals JK, Hauser RA, Olanow CW. Electromyographic studies on orthostatic tremor. Movement Disorders 1992;7(suppl 1):45.

6 Elble RJ, Koller WC. Tremor. Baltimore: Johns Hopkins University Press, 1990.

7 Papa SM, Gershanik OS. Orthostatic tremor: an essential tremor variant? Movement Disorders 1988;3:97-108.

8 Wills AJ, Jenkins IH, Thompson PD, Findley LJ, Brooks DJ. Abnormal bilateral cerebellar activation in orthostatic tremor. Neurology 1994;44(suppl 2):A369.

9 Fitzgerald PM, Jankovic J. Orthostatic tremor: an association with essential tremor. Movement Disorders 1991;6:60-4.

10 Deuschl G, Luecking CH, Quintern J. Orthostaticher Tremor: Klinik, Pathophysiologie und Therapie. EEG EMG 1987;19:13-9.

\section{Assessing the consequences of changing childbirth}

\section{Better data are needed}

Pregnancy care in Britain is changing, ${ }^{1}$ and the results of these changes need to be monitored. At first sight this seems easy. Obstetricians and midwives have always led the way in clinical audit. The confidential enquiry into maternal deaths was established over 40 years ago, ${ }^{2}$ and perinatal mortality is carefully reviewed locally. ${ }^{3}$ In research, perinatal medicine stands out from other specialties in its systematic reviews of randomised controlled trials. ${ }^{45}$

Nevertheless, standards of audit and data collection are falling, not rising. In the most recent report on maternal deaths $^{6}$ medical information was missing in $4 \%$ of cases, compared with $0.4 \%$ in the previous report. The maternity hospital inpatient inquiry has been replaced by a hospital episode system, which is notoriously incomplete, and we now lack reliable figures for such basic concerns as national rates of caesarean section and planned home delivery. ${ }^{7}$ In the 1980 s the Office of Population Censuses and Surveys achieved almost perfect records of birth weight, but now it is missing data, particularly those relating to very small babies. ${ }^{\text {? }}$

This lack of rigour in the collection of important statistics may be a symptom of a wider malaise (the 1991 national census missed more people than ever before ${ }^{8}$ ) but specific causes can be suggested. The Office of Population Censuses and Surveys has suffered financial constraints. ${ }^{7}$ Statistics have received low priority in the NHS reforms. Trusts do not have a culture of collecting and publishing information on the public health. The reorganisation of regions has led to the loss of staff skilled in collecting data. There is no routine census of maternity units - though, because most units train junior doctors, information is gathered by the Royal College of Obstetricians and Gynaecologists.

A new report from the National Perinatal Epidemiology Unit discusses how to obtain better information about pregnancy care. ${ }^{7}$ Data on maternal deaths, for example, could be improved by a simple change in death certification which has been called for by all four chief medical officers in the United Kingdom. ${ }^{6}$ This, however, requires legislation, and parliamentary time is not available-presumably because safety in pregnancy is no longer politically important. It should be. Both maternal ${ }^{6}$ and perinatal ${ }^{9}$ mortality seem higher among ethnic minorities, and better data would allow resources to be targeted where they are most needed.

More antenatal care is now being given outside hospitals, but we have few statistics on the general practitioners' involvement and inadequate national data about the work of community midwives. We would know more if hospital based information systems were replaced or supplemented by pregnancy based systems-a realistic prospect. Discussions are well under way about a national woman held pregnancy record, based on one developed in the West Midlands region. Combined with a "smart card" (with adequate safeguards and reassurances), these records could provide good pregnancy based data.

Much of the morbidity of pregnancy occurs in the weeks after childbirth, ${ }^{10}$ and this morbidity sometimes leads to chronic ill health. ${ }^{7}$ This is hardly recognised by professionals, let alone recorded in official statistics. A pregnancy based record should continue into the puerperium. Routine collection of data collection after the puerperium would facilitate research into links between pregnancy care and subsequent child health.

Once reliable data were available from either an improved hospital episode system or a new system, further analysis could be achieved by computer linkage. In the North West Thames region all 15 maternity units are linked to a computer system, ${ }^{11}$ which is now producing accurate and consistent data. ${ }^{12}$ NHS systems could also be linked to the Office of Population Censuses and Surveys to facilitate the collection of data on birth weight.

The building blocks of a good system are scattered around Britain, but what is missing is any sense of urgency about putting them together. We need better "linkage" between those who gather information and those who could use it. Accurate statistics are important not in themselves but as an aid to the provision of better care for the women and babies who need it most.

JAMES OWEN DRIFE

General Infirmary,

Professor of obstetrics and gynaecology

Leeds LS2 9NS

1 Department of Health. Changing childbirth. London: HMSO, 1993.

2 Godber G. The origin and inception of the confidential enquiry into maternal deaths. $\mathrm{Br} f$ Obster Gynaecol 1994;101:946-7.

3 Settatree RS, Watkinson $M$. Classifying perinatal death: experience from a regional survey. $\mathrm{Br} \mathfrak{F}$ Obstet Gynaecol 1993;100:110-21.

4 Grant A. Randomized trials in perinatology: major achievements and future potential. Ann NY Acad Sci 1993;703:107-17.

5 Chalmers I, Enkin M, Kierse MINC. Effective care in pregnancy and childbirth. Oxford: Oxford University Press, 1989.

6 Department of Health. Report on confidential enquiries into maternal deaths in the United Kingdom 1988-1990. London: HMSO, 1994.

7 Macfarlane A, Mugford M, Johnson A, Garcia J. Counting the changes in childbirch: trends and gaps in national statistics. Oxford: National Perinatal Epidemiology Unit, 1995.

Hawkes N. Census missed a million of the neediest people. Times 1995 Jan 6:8.

8 Hawkes N. Census missed a million of the neediest people. Times 1995 Jan 6:8.

9 Lieberman E. Low birth weight-not a black-and-white issue. N Engl 9 Med 1995;332:117-8.
10 Glazener CMA, MacArthur C, Garcia J. Postnatal care: time for a change. Comtemporary Reviews in Obstetrics and Gynaecology 1993;5:130-6.

11 Paterson CM, Chapple JC, Beard RW, Joffe M, Steer PJ, Wright CSW. Evaluating the quality of maternity services-a discussion paper. Br 7 Obstet Gynaecol 1991;98:1073-8.

12 Cleary R, Beard RW, Coles J, Devlin HB, Hopkins A, Roberts S, et al. The quality of routinely collected maternity data. Br $\mathcal{O}$ Obstet Gynaecol 1994;101:1042-7. 